\title{
Enxerto de ramo mandibular para reconstrução maxilar em pacientes pós cirurgia ortognática: relato de caso
}

Mandibular ramus graft for maxillary reconstruction in patients after orthognathic surgery: case report

Injerto de rama mandibular para reconstrucción maxilar en pacientes tras cirugía ortognática: reporte de caso

João Roberto Trindade Costa Filho

ORCID: https://orcid.org/0000-0002-2664-0116 Clínica privada, Brasil

E-mail: joaoroberto19@hotmail.com

João Victor Soares Rodrigues

ORCID: https://orcid.org/0000-0002-1812-2589

Universidade do Estado de São Paulo, Brasil E-mail: joao.vic.t@hotmail.com

Natália Barbosa de Siqueira

ORCID: https://orcid.org/0000-0003-0245-3639

Universidade do Estado de São Paulo, Brasil

E-mail: natalia_siqueira_@hotmail.com

Pedro Ivo Tavares Trindade

ORCID: https://orcid.org/0000-0003-2067-8612 Clínica privada, Brasil

E-mail: pedroitt98@gmail.com

Naara Gabriela Monteiro

ORCID: https://orcid.org/0000-0002-2857-9195

Universidade do Estado de São Paulo, Brasil

E-mail: naaragmonteiro@gmail.com

Leticia Palin Pitol

ORCID: https://orcid.org/0000-0003-4765-3765

Universidade do Estado de São Paulo, Brasil

E-mail: leticiappalin@gmail.com

Ana Cláudia Ervolino da Silva

ORCID: https://orcid.org/0000-0002-6592-0460

Universidade do Estado de São Paulo, Brasil

E-mail: anaervolino@hotmail.com

Eduardo Hochulli Vieira

ORCID: https://orcid.org/0000-0003-4040-9313

Universidade do Estado de São Paulo, Brasil

E-mail: eduardo.hochulli@unesp.br

Belmiro Cavalcanti do Egito Vasconcelos

ORCID: https://orcid.org/0000-0002-6515-1489

Universidade de Pernambuco, Brasil

E-mail: belmirovasconcelos@gmail.com

\begin{abstract}
Resumo
A ausência de tecido ósseo remanescente dos rebordos alveolares tem sido um grande problema para a reabilitação estética e funcional nos pacientes. O enxerto ósseo autógeno é o material ideal para reconstrução dos rebordos maxilares e mandibulares. A escolha da área doadora, seja intrabucal ou extrabucal, está relacionada com a quantidade e a qualidade do enxerto ósseo necessária para cada caso. O presente estudo tem por objetivo relatar um caso clínico de reconstrução maxilar em paciente após cirurgia ortognática utilizando-se como área doadora, a região de ramo mandibular, e revisar as principais características relacionadas à técnica cirúrgica.
\end{abstract}

Palavras-chave: Transplante ósseo; Maxila; Reabilitação bucal.

\section{Abstract}

The absence of remaining bone tissue from the alveolar ridge has been a major problem for aesthetic and functional rehabilitation in patients. The autogenous bone graft is the ideal material for reconstruction of the maxillary and 
mandibular borders. The choice of donor area, whether intraoral or extraoral, is related to the quantity and quality of the bone graft required for each case. The present study aims to report a case clinical study of maxillary reconstruction in a patient after orthognathic surgery using the donor area, the mandibular branch region, and to review the main characteristics related to the surgical technique.

Keywords: Bone transplantation; Maxila; Mouth rehabilitation.

\section{Resumen}

La ausencia de tejido óseo remanente de los bordes alveolares ha sido un problema importante para la rehabilitación estética y funcional de los pacientes. El injerto óseo autógeno es el material ideal para la reconstrucción de los bordes maxilar y mandibular. La elección de la zona donante, ya sea intraoral o extraoral, está relacionada con la cantidad y calidad del injerto óseo requerido en cada caso. El presente estudio tiene como objetivo reportar un caso clínico de reconstrucción maxilar en un paciente postoperatorio de cirugía ortognática utilizando la región de la rama mandibular como área donante, y revisar las principales características relacionadas con la técnica quirúrgica.

Palabras clave: Trasplante de hueso; Mandíbula; Rehabilitación oral.

\section{Introdução}

Reabsorção do osso alveolar é um problema clínico comum que pode ser um processo fisiológico ou patológico. A perda dentária provoca a reabsorção do osso alveolar e a consequência é a alteração da morfologia do rebordo. Esta alteração ocorre porque o processo alveolar tem a função de dar sustentação aos dentes, perdida esta função sua tendência é reabsorver gradativamente (Branemark et al., 1975; Ashman et al.,1985). A reabsorção do processo alveolar envolve a redução de tamanho sagital e/ou vertical dos maxilares, levando assim, a uma discrepância das relações intermaxilares e à anormalidade funcional prejudicando a mastigação (Tonelli et al., 2011).

A perda prematura dos elementos dentários acarreta mudanças na estrutura óssea. O osso alveolar, as estruturas de sustentação e o próprio dente compõem um complexo sistema que se mantém em equilíbrio fisiológico e biológico. Uma vez que se rompe este quadro, todo o sistema sofre mudanças e consequências. Nesse caso, o osso começou a ser reabsorvido muito antes da cirurgia ortognática. O grau de reabsorção óssea pode variar entre indivíduos, demonstrando a existem de forças biomecânicas que controlam e regulam o processo de remodelamento ósseo (Matocano et al.,2004).

As áreas doadoras comumente utilizadas são classificadas em intrabucais e extrabucais (Neves, 2002). E sua escolha varia de acordo com uma série de fatores. A linha oblíqua externa e a sínfise mentoniana, fontes intrabucais, acumulam vantagens por apresentarem osso medular, fundamental na revascularização do enxerto, e volume satisfatório para reconstruir defeitos correspondentes a vários dentes (Jensen et al., 1995).

Transplantes autógenos são os enxertos mais previsíveis na reconstrução estética de grandes atresias ósseas. O enxerto da região retro-molar fornece grande quantidade de osso cortical e pouca medular (Manso, 2001). O presente estudo tem por objetivo relatar um caso clínico de reconstrução maxilar em paciente após cirurgia ortognática, utilizando-se como área doadora a região de ramo mandibular, bem como, revisar as principias características relacionadas à técnica cirúrgica.

\section{Relato de Caso}

Paciente do gênero feminino, 35 anos de idade, sem histórico médico relevante e sem queixas sintomatológicas, foi submetido a cirurgia Ortognática no serviço de Cirurgia Buco-maxilo-facial do Hospital Universitário Oswaldo Cruz da Universidade de Pernambuco, Recife, Brasil. Após cinco meses (Figuras 1 e 2), por apresentar perda dos elementos dentais anteriores da maxila, com presença de severa atrofia maxilar anterior sem quantidade óssea suficiente para uma reabilitação total, foi proposto uma cirurgia de reconstrução óssea (Figura 3). 
Research, Society and Development, v. 10, n. 2, e48010212756, 2021

(CC BY 4.0) | ISSN 2525-3409 | DOI: http://dx.doi.org/10.33448/rsd-v10i2.12756

Figura 1: Paciente pré cirurgia ortognática. A, C: Vista de perfil; B: Vista frontal.

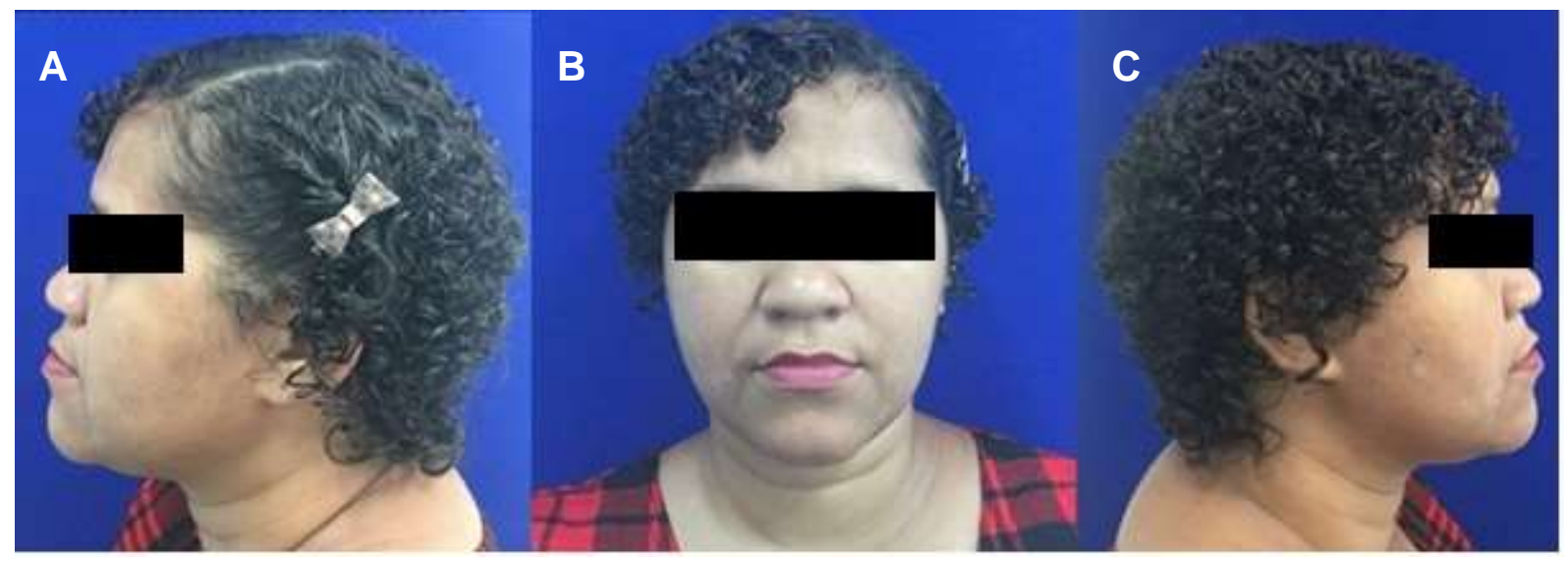

Fonte: Autores.

Figura 2: Paciente 5 meses pós cirurgia ortognática. A, C: Vista de perfil; B: Vista frontal.

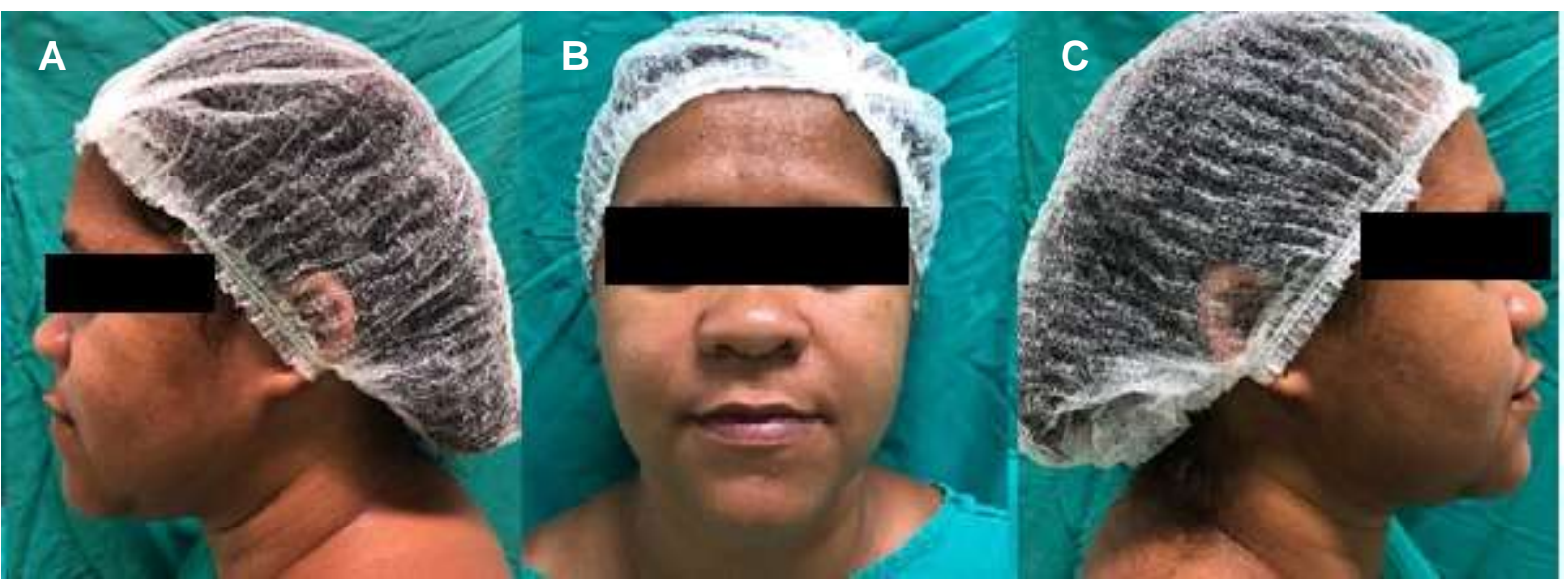

Fonte: Autores.

Figura 3: Pré operatório. A: Tomografia de feixe cônico; B: Vista frontal com sorriso forçado; C: Intra-oral.

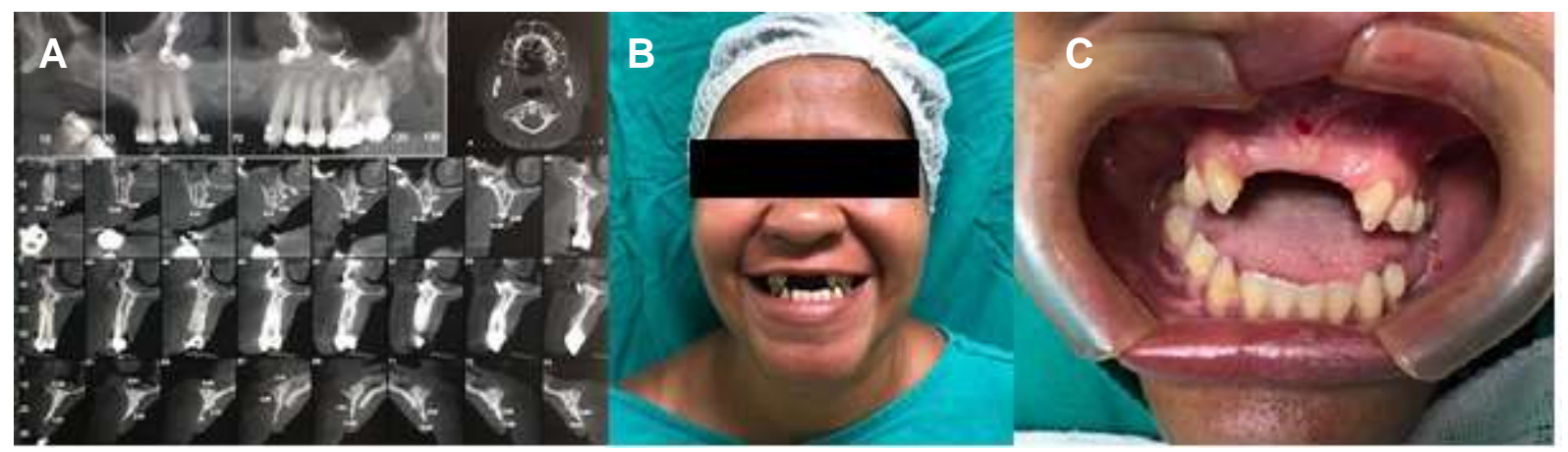

Fonte: Autores.

Durante exame físico constatou-se um perfil facial satisfatório, onde apresentava ausência dentária na região dos incisivos superiores e molares inferiores (Figura 2). Em seu procedimento de cirurgia ortognática, foi realizado avanço maxilar e recuo do mento mandibular para compensar a deformidade facial e diminuir riscos transoperatórios. 
Ao exame de imagem notaram-se placas de titânio bem adaptadas em posição planejada na região de maxila e mento, com consolidação óssea. Na região de maxila anterior, apresentava além da ausência dentária uma perda óssea considerável com uma altura máxima de 13,30 mm e mínima de 10,84 e espessura máxima de 3,08 mm e mínima de 1,41 mm, constatando-se a necessidade de reconstrução do osso alveolar em região anterior de maxila através de enxerto ósseo, a fim de viabilizar a instalação de implantes dentários (Figura 3).

Sob anestesia geral, foi realizado a cirurgia de reconstrução maxilar, o qual foi removido osso autógeno da região de ramo mandibular esquerdo, fixação do enxerto em região anterior de maxila com parafuso bicortical, complementação com osso particulado, instalação de membrana e fechamento de retalho. Para tanto se realizou uma incisão de Newman modificada em região de maxila para exposição da região receptora, em seguida uma incisão em linha obliqua externa, removendo o osso da região do ramo mandibular após descolamento total do retalho. Utilizando-se do planejamento tomográfico prévio foi observado o posicionamento do nervo alveolar inferior e o volume ósseo presente na área do ramo mandibular. Na sequência, a região foi demarcada utilizando-se a broca esférica número $2 \mathrm{em}$ todo seu comprimento. As marcações foram unidas utilizando-se a broca 701. Para fragilizar a base do bloco utilizou-se uma broca esférica longa, número 8, lateralmente, fazendo uma canaleta unindo osteotomias verticais (Figura 4). Em seguida, com o auxílio de cinzéis finos e martelo clivou-se o bloco ósseo que foi armazenado em recipiente estéril. As margens ósseas foram arredondadas com uma broca esférica de corte cruzado e o osso particulado coletado. Por fim, reposicionou-se o retalho com o fio de Nylon 4-0, fazendo ponto simples. Em seguida, foi inserido o enxerto na região maxilar e fixado com um parafuso bicortical para fixação. Após instalação do enxerto foi realizado a complementação dos espaços vazios com enxerto alógeno particulado e recoberto com membrana de colágeno reabsorvivel e por fim suturado com Nylon 5-0 (Figura 5).

Figura 4: Trans-operatório. A: Maxila (área receptora) com acesso realizado; B: Ramo mandibular (área doadora) com acesso realizado; C: Ramo mandibular pós marcação e osteotomia.

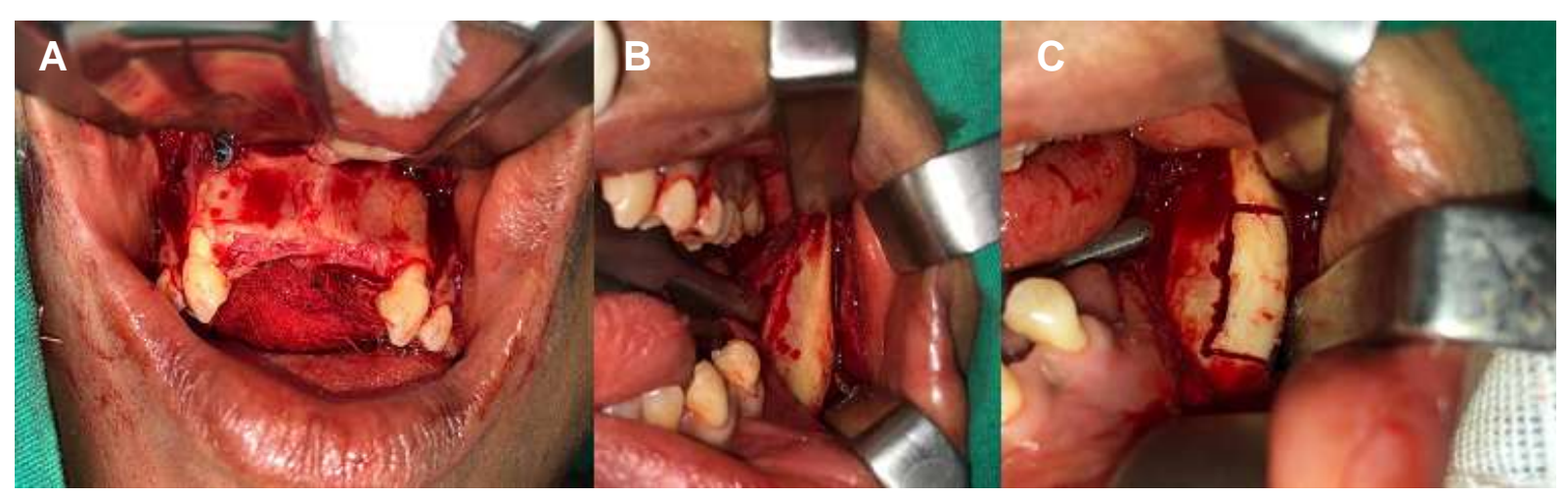

Fonte: Autores. 
Figura 5: Trans-operatório. A: Enxerto de ramo mandibular fixado em maxila; B: Complementação com enxerto alógeno; C: Sutura.

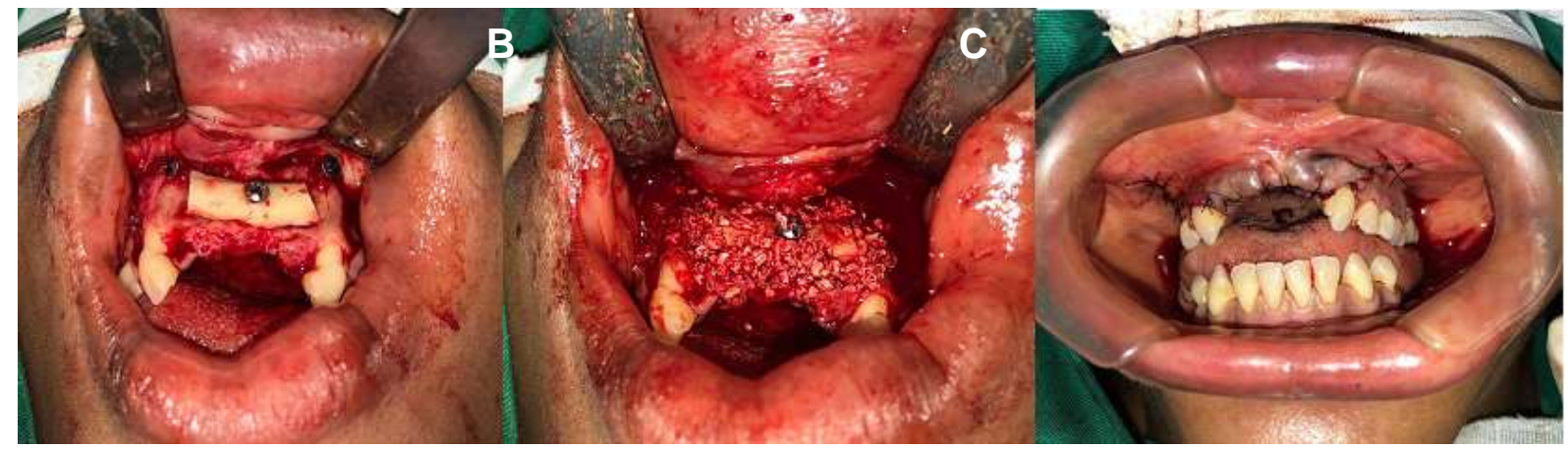

Fonte: Autores.

No momento a paciente encontra-se em acompanhamento pós-operatório com 80 dias, não apresentando nenhum tipo de complicação. Em seu exame de imagem foi possível observar um processo de neoformação óssea em região de maxila, e clinicamente existia uma maior projeção maxilar e com futura instalação de implantes dentários para uma reabilitação completa. O planejamento da cirurgia ortognática foi executado levando em consideração os padrões de planejamento e técnicas atuais (Figura 6).

Figura 6: Pós cirúrgico 80 dias. A: Intra-oral; B: Raio X Panorâmica.
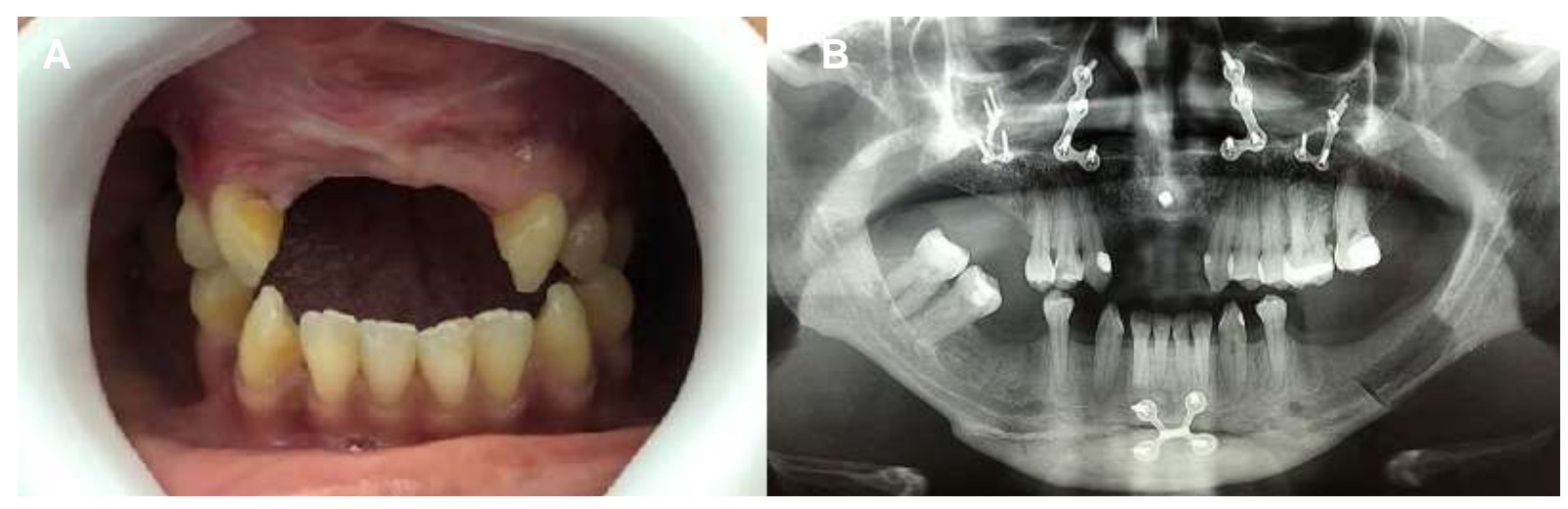

Fonte: Autores.

\section{Discussão}

Para prover uma adequada reabilitação óssea, obtendo-se estética satisfatória e bons resultados das funções mastigatória e fonética, em casos onde há perda óssea considerável é usualmente necessário a reconstrução óssea do rebordo alveolar. Os enxertos ósseos são amplamente indicados para este fim (Monnazzi et al., 2013). Os enxertos podem ser obtidos através de sítios cirúrgicos intra-orais ou extra-orais. A seleção do sítio cirúrgico doador adequado deve ser determinada pela quantidade óssea necessária, tipo de defeito ósseo, pela quantidade e qualidade óssea ofertada pela área doadora, pelo grau de dificuldade em realizar o procedimento cirúrgico a fim de obter-se o enxerto, pela morbidade e complicações que podem advir desse procedimento, pelos custos que esse pode trazer, pelas condições sistêmicas do paciente e pelo planejamento da reabilitação (Gassen et al., 2008).

A fíbula, a tíbia, a costela, a calota craniana, a crista ilíaca e outros constituem algumas das áreas doadoras extra-orais. A escolha dessas áreas para obtenção de enxertos requer cirurgias extensas, com um tempo cirúrgico excessivo, com um maior grau de morbidades e complicações, além da necessidade de realização em ambiente hospitalar e equipes outras (Gassen et al., 2008). 
A utilização de sítios cirúrgicos intra-orais oferece menor morbidade, conveniência do acesso cirúrgico, não requer essencialmente a realização em ambiente hospitalar. Devem ser utilizados quando há a necessidade de pequenos enxertos. O arco zigomático, o processo coronóide, o túber maxilar, exostoses, o corpo, o ramo e a sínfise mandibular estão entre as áreas doadoras intrabucais (Gassen et al., 2008). Quando é requerido um enxerto de pequenas dimensões, o ramo e a sínfise mandibular estão entre os sítios doadores mais utilizados (Misch, 1984).

Os enxertos do ramo mandibular oferecem grande quantidade de osso cortical e pouca quantidade de osso medular, sendo assim utilizados sobrepostos ao remanescente ósseo. A anatomia local determinará a espessura e o tamanho do enxerto. $\mathrm{O}$ acesso pode ser limitado pelo fato da região estar na parte posterior da cavidade bucal. A incisão deve ser realizada sobre a linha obliqua externa do ramo mandibular até a região do primeiro molar inferior ou pode ser realizada no ramo e seguir com incisão interpapilar até a região do segundo pré-molar inferior. O retalho é de espessura total. A área retro molar e a linha obliqua externa devem ser expostas através de um amplo descolamento. A região do enxerto é delimitada através de uma broca da série 700 ou com mini serras, o enxerto é, então, removido com o auxílio de cinzeis e alavancas (Jung et al., 2003).

A remoção do enxerto do ramo mandibular oferece como risco lesão ao feixe vásculo-nervoso do alveolar inferior, o que pode levar a um sangramento trans-operatório abundantes, hematoma e parestesia, lesão ao nervo lingual e fratura mandibular (Jung et al., 2003).

Embora ofereça risco de morbidade os enxertos oriundos do ramo mandibular, ainda oferecem menores riscos do que os enxertos oriundos do mento. A região do mento oferece boa quantidade e qualidade de osso cortical e medular, fornece um enxerto em forma de semiarco. $\mathrm{O}$ acesso e a técnica para sua obtenção estão bem descritos, mas exigem bom treinamento e cuidados pré, trans e pós-operatórios. Hemorragia, hematoma, edema, parestesia labial e/ou dental, apicetomia e desvitalização da polpa são algumas das complicações associadas a este procedimento (Misch, 1984).

No caso em questão optou-se pela região do ramo mandibular dado a facilidade de obtenção do enxerto, a necessidade de um enxerto de tamanho relativamente pequeno, e pelo fato da paciente ter sido submetida à uma cirurgia ortognática com mentoplastia, inviabilizando a remoção de um enxerto desta área. Também foi complementado com enxerto bio oss. Embora saiba-se que o enxerto autógeno ainda é considerado o melhor uma vez que possui propriedades osteogênicas e osteocondutoras (Schlee et al., 2014), a associação com enxertos aloplásticos são altamente previsíveis.

Segundo Maeste-Ferrin et al., (2009) e Mazzoneto et al., (2012) o uso das membranas de colágeno reabsorvíveis diminui a reabsorção do enxerto. Por outro lado, o preparo da área receptora, o tecido mole deve fornecer recobrimento do enxerto sem tensão. A utilização de incisões de alívio fornece a liberação do tecido permitindo a realização de uma sutura adequada, evitando deiscências (Schlee et al., 2014). No acaso descrito nesse artigo, realizou-se uma incisão linear com duas incisões relaxantes, a incisão de Newman modificada, a fim de obter-se melhor visualização e adequado recobrimento do enxerto, evitando-se deiscência da ferida cirúrgica.

\section{Conclusão}

As reconstruções ósseas do rebordo alveolar são complexas e demandam a seleção adequada da área doadora do enxerto. O enxerto de ramo mandibular mostrou-se adequado para o caso em questão, visto que a região do mento mandibular se tornou inviável após a realização de mentoplastia de recuo, durante a cirurgia ortognática. Ainda a área receptora do enxerto necessitava de um enxerto de pequenas proporções compatível com o sitio doador utilizado.

\section{Referências}

Ashman, A., \& Bruins, P. (1985). Prevention of alveolar bone loss postextraction with HTR graftingmaterial. Oral Surg; 60(2), 146-53. 
Research, Society and Development, v. 10, n. 2, e48010212756, 2021 (CC BY 4.0) | ISSN 2525-3409 | DOI: http://dx.doi.org/10.33448/rsd-v10i2.12756

Branemark, P. I., Lindström, J., Hallén, O., Breine, U., Jeppson, P. H., \& Ohman, A. (1975). Reconstruction ofthe defective mandible. Scand J Plast Reconstr Surg; 9(2), 116-28.

Gassen, H. T., Muner Filho, R., de Siqueira, B. M., Oliveira, S. B., \& Junior, A. N. S. (2008). Reconstrução óssea de maxila atrófica utilizando enxerto de ramo mandibular. Stomatos, 14(26), 55-63.

Jensen, J., Reiche-Fischel, O., \& Sindet-Pedersen, S. (1995). Autogenous mandibular bone grafts for malar augmentation. Journal of oral and maxillofacial surgery, 53(1), 88-90.

Jung, Y. S., Kim, H. J., Choi, S. W., Kang, J. W., \& Cha, I. H. (2003). Regional thickness of parietal bone in Korean adults. International journal of oral and maxillofacial surgery, 32(6), 638-641.

Marcelo, S. M., Eduardo, S. J., Valfrido, A. P. F., \& Mario, F. R. G. (2013). Reabilitação total de maxila com enxertointraoral: relato de caso. Rev assoc paul cir dent; 67(2):146-9.

Manso, M. C. Análise comportamental de transplantes intra-orais de blocos ósseos doados da região posterior da mandíbula. Dissertação apresentada à Universidade Camilo Castelo Branco como parte dos requisitos para obtenção do grau de Mestre em odontologia, Área de Concentração-Implantodontia. Campinas 2001; 110 pg.

Matocano, L. G. G. et al. (2004). Obtenção de enxertos ósseos da região de retromolar para reconstrução de maxila atrófica. $R G O ; 52(3), 189-193$.

Mazzonetto, R., Netto, H. D., \& Nascimento, F. F. (2012). Enxertos Ósseos em Implantodontia. In:Kluppel, L.E. Técnica cirúrgica para remoção de enxertos autógenos intrabucais. Nova Odessa: Napoleão; 8, 272-30.

Misch, C. M. (1984). Maxillary sinus augmentation for endosteal implants: org anized alternativetreatment plans. Int J Oral Implant; 4 , 49-58.

Neves, J. B. (2002). Implantodontia oral. Belo Horizonte: Rona; 8, 229-270.

Nóia, C. F., Netto, H. D. D. M. C., \& Lopes, R. O., Rodríguez-Chessa, J., \& Mazzonetto, R. (2009). Uso de enxerto ósseo autógeno nas reconstruções da cavidade bucal. Análise retrospectiva de 07 anos. Revista Portuguesa de Estomatologia, Medicina Dentária e Cirurgia Maxilofacial, 50 (4), $221-225$.

Schlee, M., Dehner, J. F., Baukloh, K., Happe, A., Seitz, O., \& Sader, R. (2014). Esthetic outcome of implant-based reconstructions in augmented bone: comparison of autologous and allogeneic bone block grafting with the pink esthetic score (PES). Head \& face medicine, 10(1), 1-10.

Tonelli, P., Duvina, M., Barbato, L., Biondi, E., Nuti, N., Brancato, L., \& Delle Rose, G. (2011). Bone regeneration in dentistry. Clinical cases in mineral and bone metabolism; 8(3), 24. 